\title{
Upaya Peningkatan Pemanfaatan Puskesmas Untuk Pelayanan Persalinan pada Dinas Kesehatan Kota Solok Tahun 2018
}

\author{
Pophy Arwin ${ }^{1 *}$, Edison ${ }^{2}$, Ambun Kadri ${ }^{3}$
}

\begin{abstract}
Abstrak
Pemanfaatan Puskesmas di Kota Solok untuk pelayanan persalinan masih rendah. Hal ini sangat timpang jika dibandingkan dengan sarana dan prasarana yang ada di Puskesmas yang sudah lengkap jika dibandingkan dengan bidan praktek swasta. Tujuan: Meningkatkan pemanfaatan Pusat Kesehatan Masayarakat (Puskesmas) dalam memberikan pelayanan persalinan di kota Solok. Metode: Penelitian ini merupakan bentuk kajian pada manajemen pemanfaatan Puskesmas di Kota Solok untuk pelayanan persalinan. Kajian ini dimulai dari mengidentifikasi akar masalah, memberikan alternatif pemecahan masalah dan beberapa intervensi untuk menyelesaikan masalah tersebut. Hasil: kajian didapatkan intervensi prioritas yang dapat dilakukan yaitu; 1). Bekerja sama dengan kegiatan PIS-PK untuk melakukan promosi tentang pelayanan persalinan yang dilakukan puskesmas, 2). Bekerja sama dengan program smash care 119 untuk melakukan promosi tentang pelayanan persalinan yang dilakukan puskesmas, 3). Bidan puskesmas/pustu/poskeskel harus melakukan promosi tentang pelayanan persalinan yang dilakukan di Puskesmas/pustu/poskeskel, 4). Melakukan pendekatan persuasif kepada ibu hamil pada saat ANC, agar ibu hamil bersalin di Puskesmas/pustu/poskeskel, 5). Peningkatan Kualitas ANC sehingga ibu hamil yang ANC di Puskesmas/Pustu/Poskeskel bisa bersalin di Puskesmas/Pustu/Poskeskel, serta 6). Memperluas wewenang Bidan Penanggung Jawab untuk melakukan promosi pelayanan persalinan melalui PWS.
\end{abstract}

Kata kunci: pemanfaatan puskesmas, persalinan, promosi

\begin{abstract}
The use of primary health care in Solok City for delivery services is still low. This is very unequal compared to the facilities and infrastructure in the Puskesmas that are complete compared to private practice midwives. Objectives: To improved the utilization of Community Health Centers in providing delivery services in the city of Solok. Methods:This research was a form of study on the utilization of Primary Health care in Solok City for delivery services. This study started from identifying the root of the problem, providing alternative problem solving and several interventions to solve the problem. Results: This study found that priority interventions could be carried out namely; 1). Cooperates with PIS-PK activities to conduct promotions on delivery services performed by Primary Health care , 2). Working closely with the 119 smash care program to conduct promotions on the press service provided by puskesmas, 3). Primary Health care midwives must carry out promotions on delivery services performed in Primary Health care, 4). Persuasive approach to pregnant women at the time of Antenatal Care, so that pregnant women give birth at the health center, 5). Quality Improvement of Antenatal Care so that Antenatal Care pregnant women in Primary Health care can give birth at the Primary Health care, and 6). Expanding the authority of the Responsible Midwife to promote delivery services.
\end{abstract}

Keywords: utilization of puskesmas, childbirth, promotion 
Affiliasi penulis: 1. Prodi Magister Kesehatan Masyarakat Fakultas Kedokteran Universitas Andalas. 2. Bagian IImu Kesehatan Masyarakat Fakultas Kedokteran Universitas Andalas. 3. Dinas Kesehatan Kota Solok

Korespondensi: Ambun Kadri, Email: phi111184@gmail, Hp: 081374294363

\section{PENDAHULUAN}

WHO menyebutkan bahwa setiap hari di seluruh dunia sekitar 830 wanita meninggal karena kehamilan atau persalinan dan komplikasinya. Pada beberapa Negara, ratio kematian ibu hamil adalah sekitar 2,3 \% (kematian ibu per 100.000 kelahiran hidup) pada tahun 1990-2015. Angka kematian ibu di negara berkembang adalah 239 per 100.000 kelahiran hidup dan 12 per 100.000 kelahiran hidup di negara maju pada tahun 2015. ${ }^{1}$ Kematian ibu dalam persalinan dapat dikurangi antenatal care yang baik. ${ }^{2}$

Kebijakan Kementerian Kesehatan dalam dekade terakhir menekankan agar setiap persalinan ditolong oleh tenaga kesehatan dalam rangka menurunkan kematian ibu dan kematian bayi, namun persalinan ditolong oleh tenaga kesehatan tetapi tidak dilaksanakan di fasilitas pelayanan kesehatan, dianggap menjadi salah satu penyebab masih tingginya Angka Kematian Ibu. Pada tahun 2015, penekanan persalinan yang aman adalah persalinan ditolong tenaga kesehatan di fasilitas pelayanan kesehatan. Rencana Strategis Kementerian Kesehatan tahun 2015-2019 menetapkan persalinan di fasilitas pelayanan kesehatan sebagai salah satu indikator upaya kesehatan ibu, menggantikan pertolongan persalinan oleh tenaga kesehatan. ${ }^{3}$

Riset Kesehatan Dasar (Riskesdas) 2013 menyebutkan bahwa 70,4\% persalinan dilakukan di fasilitas pelayanan kesehatan dan 29,6\% persalinan masih dilakukan dirumah/lainnya, jika dilihat dari penolong persalinan, maka $87,1 \%$ persalinan ditolong oleh tenaga yang kompeten (dokter spesialis, dokter umum dan bidan), sedangkan $12,9 \%$ persalinan ditilong oleh tenaga yang jkurang kompeten. ${ }^{3}$

Ada $88,55 \%$ ditolong oleh tenaga kesehatan dengan $79,72 \%$ persalinan oleh tenaga kesehatan dilakukan di fasilitas kesehatan dan 8,83\% persalinan oleh tenaga kesehatan dilakukan di fasilitas non kesehatan. Di Provinsi Riau, terdapat 84\% persalinan ditolong oleh tenaga kesehatan, 57,12 \% persalinan nakes dilakukan di fasilitas pelayanan kesehatan dan
27,31\% persalinan nakes dilakukan di non fasilitas pelayanan kesehatan. Pada Provinsi Sumatera Barat, $81,84 \%$ persalinan ditolong oleh tenaga kesehatan, $78,55 \%$ persalinan nakes dilakukan di fasilitas pelayanan kesehatan dan $3,31 \%$ persalinan nakes dilakukan di non fasilitas pelayanan kesehatan. ${ }^{3}$

Laporan seksi Kesehatan Keluarga Kota Solok menyimpulkan bahwa dari 1.310 persalinan tahun 2017, 0,19\% persalinan dilakukan di Puskesmas, 48\% persalinan dilakukan di Bidan Praktek Swasta, 29\% persalinan dilakukan di Rumah Sakit lbu dan Anak dan 22.81\% dilakukan di Rumash Sakit Umum. ${ }^{4}$

Berdasarkan data tersebut, pemanfaatan Puskesmas di Kota Solok untuk pelayanan persalinan masih rendah. Hal ini sangat timpang jika dibandingkan dengan sarana dan prasarana yang ada di Puskesmas yang sudah lengkap dan lebih lengkap jika dibandingkan dengan Bidan Praktek swasta.

Penelitian yang dilakukan oleh Ai Irmayati (2013) menyebutkan bahwa variabel sikap, biaya persalinan, keterpaparan informasi serta dukungan keluarga, tokoh masyarakat, teman dan tetangga sangat berhubungan dengan penggunaan pelayanan persalinan. $^{5}$

Berdasarkan hal diatas, kajian ini dilakukan agar bisa mengidentifikasi akar masalah penyebab rendahnya pemanfaatan puskesmas sebagai tempat pertolongan persalinan di Kota Solok.

\section{METODE}

Kajian ini dilakukan dengan mengindentifikasi akar masalah rendahnya pemanfaatan puskesmas sebagai tempat pertolongan persalinan dengan menggunakan diagram ishikawa (fishbone analysis), berdasarkan data sekunder dan primer dengan melakukan wawancara dan observasi. Dari akar masalah tersebut dicari alternatif pemecahan masalah yang dilakukan melalui brain stroming dan focused group discussion dengan Kepala Dinas dan para pelaksana program.

\section{HASIL}

\section{Analisis Akar Masalah}

Berdasarkan data yang diperoleh dan hasil wawancara dengan Kepala Dinas, Kepala Puskesmas, dan ibu hamil didapatkan beberapa penyebab 
masalah adanya rendahnya pemanfaatan puskesmas untuk pelayanan persalinan pada Dinas Kesehatan Kota Solok, yaitu :

a. Manusia

1. Kurangnya minat ibu hamil untuk bersalin di Puskesmas

2. Persepsi ibu hamil yang beranggapan bahwa pelayanan BPS/klinik lebih baik dari puskesmas

3. Kurangnya promosi diri bidan puskesmas/pustu/poskeskel tentang pelayanan persalinan yang dilakukannya

4. Sikap dari petugas kesehatan yang kurang ramah

b. Dana

1. Belum adanya anggaran pengadaan sarana penunjang kamar rawatan

c. Lingkungan

1. Kebiasaan sesama ibu hamil yang periksa di BPS

2. Dukungan suami untuk persalinan

3. Riwayat persalinan keluarga dan sebelumnya

4. Kurangnya kerjasama lintas sektoral

d. Material

1. Tipe dan Jenis Puskesmas

2. Belum nyamannya ruangan perawatan di puskesmas

3. Kurangnya media (poster, leaflet) tentang adanya pelayanan persalinan di puskesmas

e. Metode

1. Belum komperhensifnya ANC

2. Pelayanan penunjang yang belum komperhensif

3. Kurangnya promosi dari puskesmas tentang adanya pelayanan persalinan puskesmas

4. Wewenang PWS diperluas

5. Komitmen yang kuat antara kepala dinas dan jajarannya

Berdasarkan indentifikasi akar masalah diatas maka ditetapkan beberapa solusi pemecahan masalah pada setiap levelnya yaitu ;

1. Manusia

- Penyuluhan/konseling tentang pelayanan persalinan yang dilakukan di Puskesmas
- Penyuluhan tentang pelayanan yang diberikan di Puskesmas

- Kerjasama dengan Kader, Toma dan Toga untuk memberikan penyuluhan/konseling tentang pelayanan yang diberikan di puskesmas

- Bidan puskesmas/pustu/poskeskel harus melakukan promosi tentang pelayanan persalinan yang dilakukan di Puskesmas/pustu/poskeskel

- Melakukan pelatihan capacity building untuk pembangunan karakter

2. Metode

- Bekerja sama dengan program smash care 119 untuk melakukan promosi tentang pelayanan persalinan yang dilakukan puskesmas

- Bekerja sama dengan kegiatan PIS-PK untuk melakukan promosi tentang pelayanan persalinan yang dilakukan puskesmas

- Meningkatan pelayanan penunjang di pelayanan persalinan di Puskesmas seperti fasilitas laundry

- Peningkatan Kualitas ANC sehingga ibu hamil yang ANC di Puskesmas/Pustu/Poskeskel bisa bersalin di Puskesmas/Pustu/Poskeskel

- Pembentukkan komitmen yang kuat antara kepala dinas dan jajaran

3. Dana

- Advokasi kepada pihak terkait seperti DPRD untuk memasukan kegiatan pelayanan persalinanke dalam APBD

4. Lingkungan

- Kerjasama dengan BPS untuk melakukan mitra bidan pustu/poskeskel dengan bidan praktek swasta

- Menyiapkan dan memberikan kesempatan kepada suami untuk menemani ibu saat bersalin

5. Material

- Pengadaan media promosi (poster dan leaflet) tentang adanya pelayanan persalinan di puskesmas

- Peningkatan kenyamanan ruangan perawatan dengan penambahan fasilitas pendingin ruangan, televisi dan lemari baju 
Pemilihan alternatif pemecahan masalah tersebut dengan melakukan brain stroming dan focused group discussion dengan Kepala Dinas dan para pelaksana program.

Program intervensi prioritas yang dapat direncanakan untuk Peningkatan Pemanfaatan Puskesmas untuk pelayanan persalinan di Kota Solok yaitu:

1) Bekerja sama dengan kegiatan PIS-PK untuk melakukan promosi tentang pelayanan persalinan yang dilakukan puskesmas

2) Bekerja sama dengan program smash care 119 untuk melakukan promosi tentang pelayanan persalinan yang dilakukan puskesmas

3) Bidan puskesmas/ pustu/ poskeskel harus melakukan promosi tentang pelayanan persalinan yang dilakukan di Puskesmas/pustu/poskeskel

4) Melakukan pendekatan persuasif kepada ibu hamil pada saat ANC, agar ibu hamil bersalin di Puskesmas/pustu/poskeskel

5) Peningkatan Kualitas ANC sehingga ibu hamil yang ANC di Puskesmas/Pustu/Poskeskel bisa bersalin di Puskesmas/Pustu/Poskeskel

6) Memperluas wewenang Bidan Penanggung Jawab untuk melakukan promosi pelayanan persalinan melalui PWS.

\section{PEMBAHASAN}

Program intervensi yang direncanakan lebih bersifat membangun perilaku, hal ini dikarenakan dalam memanfaatkan pelayanan persalinan di Puskesmas, perubahan perilaku akan lebih memberi daya ungkit yang kuat.

Intervensi dalam bentuk bekerja sama dengan kegiatan PIS-PK untuk melakukan promosi tentang pelayanan persalinan yang dilakukan puskesmas dan bekerja sama dengan program smash care 119 untuk melakukan promosi tentang pelayanan persalinan yang dilakukan puskesmas, penulis sudah mencoba untuk melakukannya, dengan harapan kegiatan ini dapat meningkatkan jumlah persalinan di puskesmas.

Dalam kegiatan ini, dilakukan kontak langsung dengan masyarakat dan meyakinkan secara langsung kepada masyarakat bahwa persalinan yang dilakukan di Puskesmas juga aman dan nyaman.
Kegiatan ini juga dapat memberikan informasi tentang kenapa masyarakat kurang berminat untuk melakukan pelayanan persalinan di Puskesmas.

Intervensi ini merupakan salah satu contoh metode promosi individual (perorangan). Metode yang bersifat individual ini digunakan untuk membina perilaku baru atau membina seseorang yang telah mulai tertarik kepada suatu perubahan perilaku atau inovasi. Yang menjadi dasar kenapa metode ini digunakan karena masing-masing individu mempunyai masalah atau alasan yang berbeda-beda dan ini juga berhubungan dengan penerimaan atau perilaku baru tersebut. $^{6}$

Hal ini juga didukung oleh penelitian yang dilakukan Irmayati (2013) yang menyatakan bahwa masyarakat yang mendapatkan informasi tentang pelayanan persalinan di Puskesmas berpeluang lebih besar untuk memmanfaatkan pelayanan persalinan di Puskesmas. $^{5}$

Penulis berpendapat bahwa untuk meningkatkan pelayanan persalinan di Puskesmas perlu perubahan perilaku dari sisi provider atau tenaga kesehatannya yaitu bidan.Kegiatan yang direncanakan tersebut yaitu bidan puskesmas/ pustu/ poskeskel harus melakukan promosi tentang pelayanan persalinan yang dilakukan di puskesmas/pustu/ poskeskel. Pendekatan persuasif kepada ibu hamil pada saat ANC, agar ibu hamil bersalin di Puskesmas/pustu/poskeskel.

\section{SIMPULAN}

Program intervensi prioritas upaya peningkatan pemanfaatan puskesmas dalam pelayanan persalinan yaitu: 1) Bekerja sama dengan kegiatan PIS-PK untuk melakukan promosi tentang pelayanan persalinan yang dilakukan puskesmas; 2) Bekerja sama dengan program smash care 119 untuk melakukan promosi tentang pelayanan persalinan yang dilakukan puskesmas; 3) Bidan puskesmas/pustu/poskeskel harus melakukan promosi tentang pelayanan persalinan yang dilakukan di Puskesmas/pustu/poskeskel; 4) Melakukan pendekatan persuasif kepada ibu hamil pada saat ANC, agar ibu hamil bersalin di Puskesmas/pustu/poskeskel; 5) Peningkatan Kualitas ANC sehingga ibu hamil yang ANC di 
Puskesmas/Pustu/Poskeskel bisa bersalin di Puskesmas/Pustu/Poskeskel; dan 6) Memperluas wewenang Bidan Penanggung Jawab untuk melakukan promosi pelayanan persalinan melalui PWS.

\section{SARAN}

Peningkatan keterlibatan berbagai pihak perlu dilakukan dalam implementasi kebijakan program gizi dan KIA antara lain kementerian dan lembaga, dunia usaha, mitra pembangunan internasional, lembaga sosial kemasyarakatan, dan didukung oleh organisasi profesi, perguruan tinggi, serta media massa.

\section{UCAPAN TERIMA KASIH}

Terima kepada semua yang turut membantu dalam penyelesaian penelitian ini yaitu Dinas Kesehatan Kota Solok,Puskesmas Tanah Garam dan Poskelkel Tanah Garam

\section{DAFTAR PUSTAKA}

1. World Health Organization (WHO). Fact sheet. maternal mortality. 2016 [diakses 24 Januari
2018]. Tersedia dari: http://www.who.int/gho/ maternal health/en

2. Maghfirah N. Faktor-faktor yang berhubungan dengan rencana pemanfaatan pelayanan persalinan oleh pasien antenatal care di rumah sakit Muhammadiyah Taman Puring tahun 2017. [skripsi]. Jakarta: Universitas Islam Negeri (UIN) Syarif Hidayatullah; 2017.

3. Kementerian Kesehatan RI (Kemenkes RI). Profil kesehatan Indonesia 2016. Jakarta: Kemenkes RI; 2017.

4. Dinas Kesehatan Kota Solok (Dinkes Kota Solok). Profil dinas kesehatan kota Solok tahun 2016. Solok: Dinkes Kota Solok; 2017.

5. Irmayati A, Kresno S. Faktor-faktor yang berhubungan dengan penggunaan pelayanan persalinan di puskesmas Bojong Rawalumbu kelurahan Bojong Rawalumbu Kecamatan Rawallumbu kota Bekasi. 2012. [diakses 24 Januari 2018]. Tersedia dari: http://www.lib.ui.ac. id/naskahringkas/2015-09/s53320-ai\%20irmayati

6. Notoatmodjo S. Kesehatan masyarakat ilmu dan seni. Jakarta: Rineka Cipta; 2007. 